\title{
A survey of the causes of sudden death in sport in the Republic of Ireland
}

Fionnuala Quigley

\begin{abstract}
Background-Sudden death in sport is rare, but when it occurs the effects are devastating. There have not been any reports to date describing the frequency and causes of sudden death in sport in the Republic of Ireland.

Aim-To describe the incidence, possible causes, associated factors, and pathological findings in people who died while exercising in the Republic of Ireland in the $\mathbf{1 0}$ year period from January 1987 to December 1996.

Methods-All 49 regional coroners in the Republic of Ireland were approached and details on all cases of sudden death in sport from 1 January 1987 to 31 December 1996 were requested. A questionnaire was used to document age, sex, participating sport, previous symptoms, previous medical investigations, circumstances of death, and main pathological finding in all reported cases. replied. A total of 51 cases of sudden death in sport were identified. The median age was 48 (range 15-78). Fifty of the deaths were of men. Golf was the most popular participating sport. In 42 cases, the pathological cause of death was atherosclerotic coronary artery disease.
\end{abstract}

Oakacre, Ballineen, Co Cork, Ireland 00353

Correspondence to: Dr F Quigley email: oakacre@gofree. indigo.ie

Accepted for publication 10 April 2000

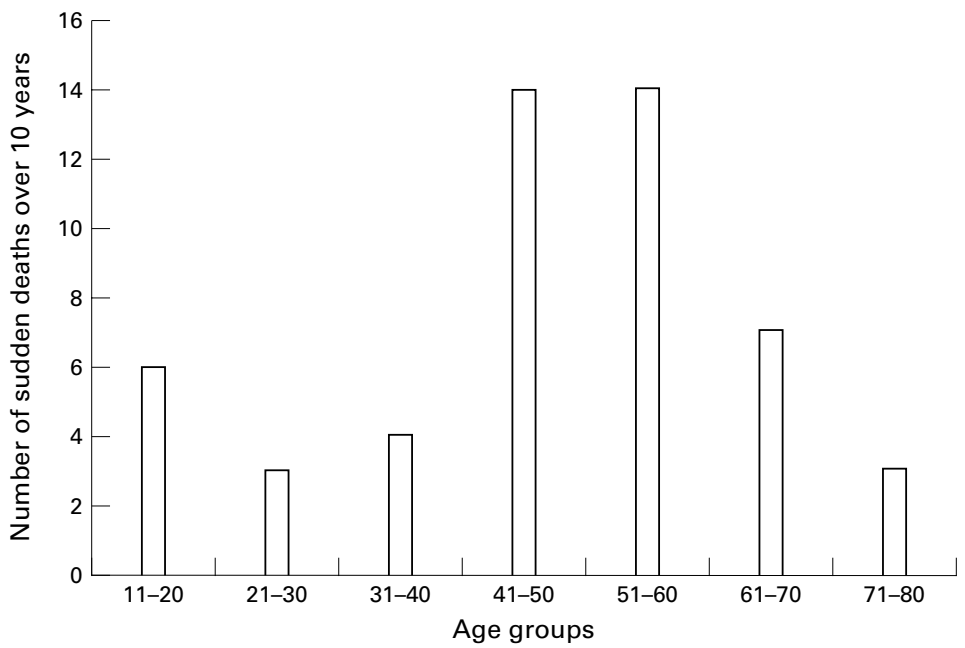

Figure 1 Age distribution of sudden deaths in sport over a 10 year period in the Republic of Ireland.
Conclusions-This is the first time the incidence of sudden death in sport in the Republic of Ireland has been described. The main cause of death in all age groups was atherosclerotic coronary artery disease. (Br f Sports Med 2000;34:258-261)

Keywords: sudden death; heart; atherosclerotic artery disease

Sudden death in sport is rare. Maron, in a study of marathon runners over a 30 year period, reported a risk of death in marathon running of 1 in $50000 .{ }^{1}$ In Ireland sudden death while exercising, particularly in young previously fit people, receives a high media profile. General practitioners most commonly encounter these cases, and the question is often asked by relatives and the media, as well as by the medical profession, whether the tragedy could have been prevented. This study aims to determine the incidence and possible aetiological factors associated with sudden death in sport in the Republic of Ireland.

\section{Method}

This retrospective study covered a 10 year period from 1 January 1987 to 31 December 1996.

There are 49 coroners in the Republic of Ireland. Each covers a specific geographical region. Once a sudden death occurs, the case is reported to the coroner in that area who in turn arranges for a post mortem to be performed.

A recording sheet was sent to all 49 coroners requesting details of age, sex, previous relevant symptoms and investigations, circumstances of death, and main pathological findings of all cases of sports related sudden death reported to them during the study period.

Sudden death has been defined as death occurring within one to 24 hours of the onset of symptoms. ${ }^{23}$ To ensure a more definite link between sudden death and sport, the definition of sudden death in sport in this study is limited to unexpected death from natural causes occurring during exercise or within one hour of engaging in a sport related activity.

\section{Results}

Of the 49 coroners surveyed, 45 replied. A total of 51 cases of sudden death in sport were reported; 50 of the these were men. The median (range) age was 48 (15-78) years (fig 1). 
Table 1 Sport played by those who died suddenly

\begin{tabular}{lr}
\hline Type of sport & No \\
\hline Golf & 16 \\
Gaelic football & 11 \\
Jogging & 5 \\
Tennis & 5 \\
Marathon & 2 \\
Soccer & 2 \\
Swimming & 2 \\
Badminton & 1 \\
Table tennis & 1 \\
Squash & 1 \\
Rugby & 1 \\
Bowls & 1 \\
Horse riding & 1 \\
10K run & 1 \\
Pitch and putt & 1 \\
\hline
\end{tabular}

Table 2 Previous symptoms in those who died suddenly

\begin{tabular}{ll}
\hline Symptoms & No \\
\hline Chest pain for a few days & 2 \\
Chest pain for a few weeks and attended GP & 2 \\
"Indigestion for a few days" & 1 \\
Chest pain earlier in the day & 1 \\
Myocardial infarction 3 years previously & 1 \\
Angina & 1 \\
Known to have a "bad heart" & 1 \\
Surgery for aortic valve stenosis & 1 \\
\hline
\end{tabular}

Table 3 Cause of death in 51 cases of sudden death in sport

\begin{tabular}{|c|c|}
\hline Cause of death & No \\
\hline Atherosclerotic coronary artery disease & 42 \\
\hline Hypertrophic cardiomyopathy & 1 \\
\hline Congenital anomaly of coronary artery & 1 \\
\hline $\begin{array}{l}\text { Multiple areas of fibrosis on myocardium } \\
\text { (no definite diagnosis) }\end{array}$ & 1 \\
\hline Cardiac arrhythmia & 1 \\
\hline Aortic stenosis & 2 \\
\hline Myocarditis & 1 \\
\hline $\begin{array}{l}\text { "Cardiac arrest ensued on aspiration of } \\
\text { stomach contents" }\end{array}$ & 1 \\
\hline $\begin{array}{l}\text { "Cardiorespiratory failure due to inhalation } \\
\text { of blood from gastric erosions; gastric acid } \\
\text { was probably also inhaled" }\end{array}$ & 1 \\
\hline
\end{tabular}

Golf was the most popular participating sport (table 1).

Five of the deceased had complained of chest pain either on the day or within days of the event (table 2). Two had a documented history of ischaemic heart disease. One had a diagnosis of "cardiac problem" but the precise nature of this was not recorded.

Forty eight of the reported sudden deaths occurred during the activity. One man collapsed immediately afterwards in the dressing room. Two deaths occurred during the journey home.

The cause of death in 42 cases was reported as atherosclerotic coronary artery disease (table 3). Three of these deaths occurred in men under the age of 35 . There was one case of hypertrophic cardiomyopathy. In another case no definite diagnosis was made even though cardiac samples were sent to a specialised unit abroad. Of the two people with aortic stenosis, one had received prior corrective surgery but had persisted in playing competitive sport. There was one case of congenital anomaly of the coronary artery and one case of probable cardiac arrhythmia in an 18 year old man who died while jogging.

An 18 year old man collapsed while playing Gaelic football, and the post mortem finding was "Cardiac arrest ensued on aspiration of stomach contents" (table 4). The post mortem findings on a 15 year old man who died while

Table 4 Cause of death in relation to age group

\begin{tabular}{lll}
\hline Cause & $\begin{array}{l}\text { No } \\
<35 \text { years }\end{array}$ & $\begin{array}{l}\text { No } \\
>35 \text { years }\end{array}$ \\
\hline Atherosclerotic coronary artery disease & 3 & 39 \\
Myocarditis & 0 & 1 \\
Aortic stenosis & 2 & \\
$\begin{array}{l}\text { Hypertrophic cardiomyopathy } \\
\text { Congenital coronary artery anomaly }\end{array}$ & 1 \\
$\begin{array}{l}\text { Cardiac arrhythmia } \\
\text { Multiple areas of fibrosis on myocardium (no definite diagnosis) } \\
\text { "Cardiorespiratory failure due to inhalation of blood from gastric } \\
\text { erosions. Gastric acid was probably also inhaled" }\end{array}$ & 1 \\
"Cardiac arrest ensued on aspiration of stomach contents" & 1 \\
\hline
\end{tabular}

playing Gaelic football was “cardiorespiratory failure due to inhalation of blood from gastric erosions; gastric acid was probably also inhaled."

The only female was a 16 year old who felt unwell while swimming. The main finding at post mortem was acute left ventricular failure due to aortic stenosis.

\section{Discussion}

This study attempts to describe the cases of sudden death in sport reported to the 49 regional coroners in the Republic of Ireland in the 10 years from January 1987 to December 1996. The population of the Republic of Ireland aged 15-80 years during this time period was about three million. Based on the findings of this study, the incidence of sudden death in sport is about 1 in 600000 population. Although there are few published data with which to compare this approximate incidence, these figures do suggest that, in the Republic of Ireland, sudden death in sport is rare. In North America, it has been calculated that there are about four deaths annually per million athletes. ${ }^{4}$

The number of deaths reported in this study for this period may be an underestimate. Some deaths in people with previously diagnosed disease who died during exercise may have been certified by their general practitioner and therefore may not have come to the attention of the coroner.

This study identified atherosclerotic coronary artery disease as the main cause of death in those over 35 who died during exercise in the Republic of Ireland during the period 19871996. This finding is in agreement with the results of other studies. ${ }^{5-8}$

There were fewer cases of hypertrophic cardiomyopathy in the younger age group than previously reported. ${ }^{9}$ Deaths in patients with previously diagnosed hypertrophic cardiomyopathy would not have to be reported to the coroner and so would not have been included in this report.

At present, the Republic of Ireland does not have a preparticipation screening programme. Therefore it is unlikely that people with hypertrophic cardiomyopathy would have been selected out to avoid all sport thereby reducing the number of deaths attributed to this disease in this study.

Although the apparently low incidence of death from hypertrophic cardiomyopathy in this study bears similarities to the findings in the Veneto region in Italy, ${ }^{10}$ it is at odds with that described in a number of other studies. ${ }^{9}$ This may reflect a truly different distribution of the disease in the Irish population compared with other populations. ${ }^{9}$ It is, however, more likely that this finding reflects under-reporting of deaths to coroners, or, given the small size of the Irish population and the relatively short time period of the study, the number of cases of hypertrophic cardiomyopathy described may reflect sampling error. Some of these issues may be addressed by the creation of a national register of deaths in sport, which may increase the reliability of reporting of these cases. 
Corrado et $a l^{10}$ have suggested that the most common cause of death in young competitive athletes in Italy may be right ventricular dysplasia. There were no reported cases of right ventricular dysplasia in this study. This may be due to the small numbers reported, or to lack of reporting of right ventricular dysplasia by general pathologists.

Myocarditis is a recognised cause of sudden death in athletes, ${ }^{11}{ }^{12}$ coxsackie B and echovirus being most commonly implicated. One reported case of sudden death during exercise in Ireland in the period 1987 to 1996 was attributed to myocarditis.

Sudden death during exercise may result from a primary arrhythmia. ${ }^{13}{ }^{14}$ In this study, there was one reported case. However, the two young people who died having inhaled gastric contents may have done so following an arrhythmia.

Exercise induced coronary artery spasm has also been described as a cause of sudden death in exercise. ${ }^{15}$ It was not observed in this study.

Aortic stenosis is associated with exercise related sudden death. ${ }^{16}$ There were two reports of death due to aortic stenosis in this survey; one of the victims had received prior corrective surgery. It is recommended that those with aortic stenosis, even if they have received surgery, should be evaluated by a doctor before they are cleared for participation in competitive sports. ${ }^{17}$

Golf is popular in Ireland and one would expect it to be played particularly by the older age group. However, two of those who died while playing golf were relatively young, aged 32 and 36.

Northcote described squash as a sport in which sudden death is relatively common. ${ }^{18}$ Squash accounts for only one of the deaths reported here. This may be because squash is not a particularly popular sport in Ireland, compared with the United Kingdom.

Gaelic football is a popular sport in the Republic of Ireland. It is a 15 person team game similar to Australian rules football, which involves sudden bursts of effort. Five men aged between 41 and 46 years died while playing Gaelic football, the cause of death being atherosclerotic coronary artery disease.

The one horse rider was a 60 year old man, who died of atherosclerotic coronary artery disease.

The under-representation of women in this study is not surprising. The estimated sports related death rates have been found to be five times greater in men. ${ }^{19}$ One reason postulated for this is the participation at higher levels of intensity among men.

As the data for this study were provided by the regional coroners rather than individual family doctors, information available on previous medical history and previous medical investigations is limited.

In conclusion, sudden death during exercise in the Republic of Ireland appears to be rare, the predominant cause, across all age groups, being atherosclerotic coronary disease. Because of the low incidence of hypertrophic cardiomyopathy identified in this study, it is difficult to justify the introduction of a preparticipation screening programme for all those involved in sport.

Despite the report's limitations, it goes some way towards informing us about what might be done to prevent sudden death in sport in the Republic of Ireland. Firstly, the results in this survey need to be prospectively validated. Secondly, as the most common cause of exercise related sudden death was atherosclerotic coronary artery disease, changes, in particular in lifestyle, must be implemented to reduce the burden of ischaemic heart disease. The urgency for this is highlighted by the fact that the age standardised mortality rates per 100000 population for ischaemic heart disease in the Republic of Ireland in 1997 was 194.4 compared with a European Union average of 114.5 in $1996 .{ }^{20}$ Of concern in Ireland are the reports from the National Health and Lifestyle survey in 1998 that only $24 \%$ of adults participate in mild (longer than 20 minutes) exercise four times a week and $21 \%$ do not exercise at all. ${ }^{21}$ Thirdly, every effort must be made to identify those with coronary artery disease in the community. This group must be carefully assessed and counselled in an attempt to minimise the risk of sudden death while exercising.

I am indebted to all the coroners in the Republic of Ireland for their enthusiastic help. Without their tremendous support this study would not have been possible. Thanks also to Margot Bolster for her invaluable contribution. Thank you, Columba and Mary for always being so positive and encouraging. Finally I would like to thank Kate for her tremendous secretarial help.

1 Maron BJ, Poliac LC, Roberts WO. Risk for sudden death associated with marathon running. $\mathcal{F}$ Am Coll Cardiol 1996;28:428-31.

2 Kuller L, Lillienfield A, Fisher R. An epidemiological study of sudden and unexpected death in adults. Medicine (Baltimore) $1967 ; 46: 341-61$.

3 Friedman M, Manaaring JH, Rosenman RH, et al. Instantaneous and sudden death: clinical and pathological differentiation in coronary artery disease. $\mathcal{F A M A} 1973 ; 225: 1319^{-}$ 28.

4 Ades PA. Preventing sudden death: cardiovascular screening of young athletes. Physician and Sports Medicine 1992;20: of young.

5 Waller BF, Newhouse P, Pless J, et al. Exercise related sudden death in 27 conditioned subjects aged $<30$ and $>30$ years; coronary artery abnormalities are the culprit. $f \mathrm{Am}$ Coll Cardiol 1984;3:621.

6 Epstein SE, Maron BJ. Sudden death and the competitive athlete: perspectives on preparticipation screening studies. f Am Coll Cardiol 1986;7:220-30.

7 Maron BJ, Epstein SE, Roberts WC. Causes of sudden death in competitive athletes. F Am Coll Cardiol 1986;7: 204-14

8 Burke AP, Farb A, Virami R, et al. Sports related and non-sports related cardiac death in young adults. Am Heart f 1991;121:568-75.

9 Maron BJ, Shirami J, Poliac LC, et al. Sudden death in young competitive athletes. Clinical, demographic and pathological profiles. fAMA 1996;276:199-204.

10 Corrado D, Thiene G, Nava A, et al. Sudden death in young competitive athletes: clinicopathologic correlations in 22 competitive athletes: clinicopatho

11 McCaffrey FM, Braden DS, Strong WB. Sudden death in young athletes. American Fournal of Disease in Children 1991;145;177-91

12 Zeppilli P, Santini C, Palmieri V, Vannicelli R, et al. Role of myocarditis in athletes with minor arrhythmias and/or echocardiographic abnormalities. Chest 1994;106; 373-80.

13 Maron BJ, Roberts WC, McAlister HA, et al. Sudden death in young athletes. Circulation 1980;62:218-29.

14 Pedersen DH, Zipes DP, Foster PR, et al. Ventricular tachycardia and ventricular fibrillation in a young population. Circulation 1979;60:988-97.

15 Yasue $\mathrm{H}$, Omote S, Takizawa A, et al. Circadian variation of exercise capacity in patients with Prinzemetal's variant angina: role of exercise induced coronary arterial spasm. Circulation 1979;59:938-48.

16 Jokl E, Melzer L. Acute fatal non-traumatic collapse during work and sport. Med Sport 1971;5:5-18. 
17 Maron BJ, Mitchell JH. 26th Bethesda Conference: recommendation for determining eligibility for competition in athletes with cardiova

18 Northcote RJ, Flanagan C, Ballantyne D. Sudden death and vigorous exercise: a study of 60 deaths associated with squash. Br Heart f 1986;55:198-203.

19 Van Camp SP, Bloor CM, Mueller FO, et al. Non traumatic sports death in high school and college athletes. Med Sci Sports Exerc 1995;27:641-7.

\section{Take home message}

Sudden death during sport in the Republic of Ireland is very rare and is predominantly caused by atherosclerotic coronary artery disease in all age groups. Because of the low incidence of hypertrophic cardiomyopathy identified here it is difficult to justify the introduction of a preparticipation screening programme.

\section{Five facts and five concepts for rehabilitation of mechanical low back pain}

\section{Five facts}

1 The prevalence of chronic or recurrent back problems is high and may be present in up to $39 \%$ of adults.

2 In the vast majority of cases it is not possible to identify a single source of pain, and findings-such as, reduced spinal movements, radiological changes, and protrusion, seen on magnetic resonance imaging have a weak correlation with the presence of back pain. ${ }^{1}$

3 Reduced straight leg raise and neurological findings are typically associated with chronic low back pain (LBP), although psychosocial factors have been identified as more significant predictors of long term disability.

4 Reduced trunk strength and physical fitness are predictors of LBP.

5 Terminology for low back pain is imprecise. Standardisation of terminology would be of great help to health care providers and patients. ${ }^{2}$

\section{Five concepts}

1 Patients with acute and chronic low back pain should be encouraged to return to normal activities as soon as possible. Exercise programmes have been shown to be effective in reducing disability although they may not affect the intensity of pain.

2 It is important to address both the somatic and psychological aspects of LBP - that is, patient beliefs, anxieties and expectations.

3 Pacing: the aims of pacing are to increase the level or amount of activity that a patient can do without increasing pain levels. This is achieved by systematically increasing activity levels (by an agreed set amount) on a daily basis from an established baseline.

4 Rehabilitation should be progressive, based on correcting truncal stabiliser dysfunction. This forms the basis of functional stabilisation programmes which begin with maintenance of the spine in a painless neutral position with use of local stabilisers. The next step is to maintain spine neutrality with added limb load. Gradually dynamic control of the spine can be addressed with retraining of global mobilisers. Functional movement retraining is essential starting with slow limb and spinal movements progressing to complex high speed ballistic actions.

5 Proprioceptive retraining is integral to the programme using wobble boards and gymnastic balls.

MARK E BATT CHERALYNNE TODD Centre for Sports Medicine, Queens Medical Centre, Nottingham NG7 2UH

1 Jason MIV. Why does acute back pain become chronic? BMF 1997;31:1639-40.

2 Fardon D, Pinkerton S, Balderston R, et al. Terms used for diagnosis by English speaking spine surgeons. Spine 1993;18:274-7. 